\title{
In vivo Development of Voltage-dependent Ionic Currents in Embryonic Xenopus Spinal Neurons
}

\author{
Michel G. Desarmenien, ${ }^{a}$ Beverly Clendening, and Nicholas C. Spitzer \\ Department of Biology and Center for Molecular Genetics, University of California at San Diego, La Jolla, California 92093
}

Initial evidence that electrical excitability is both an early aspect of neuronal differentiation and a developmentally regulated property was obtained from recordings of action potentials in vivo. Subsequently, the analysis of the underlying voltage-dependent currents during early stages of embryogenesis was facilitated by investigation of dissociated neurons and muscle cells differentiating in culture. Calcium and potassium currents play a major role in the differentiation of the action potential of Xenopus spinal neurons, and calcium influx triggers specific features of neuronal differentiation. However, the extent to which differentiation of currents in vitro parallels that in vivo is uncertain.

We have undertaken a study of in vivo differentiation of these macroscopic currents in Xenopus embryos. Spinal cords were isolated from embryos at several early stages of neurogenesis. Neurons in these isolated spinal cords were accessible to patch-clamp electrodes. Neuronal currents were recorded within $1 \mathrm{hr}$ to assure that the characteristics of the currents resulted from developmental events occurring in vivo prior to the experiment. Whole-cell voltage-clamp recordings from neurons in these acutely isolated and intact embryonic spinal cords demonstrate that both the delayedrectifier and inactivating potassium current and a low-voltage-activated calcium current mature in a manner closely parallel to that observed in culture. The results validate those from the culture system and indicate that the spinal cord is another region of the CNS accessible to cellular analysis in an intact preparation.

[Key words: potassium currents, calcium currents, neuronal differentiation, spinal cord, Xenopus embryos, wholecell recordingl

Development of the neuronal action potential and the underlying voltage-dependent currents has been examined during early stages of embryogenesis in various species (Spitzer, 1991). Most of these investigations have been carried out on dissociated cells differentiating in culture, because of the greater accessibility of the neurons. Development of currents in vivo has been in-

\footnotetext{
Received Aug. 6, 1992; revised Nov. 23, 1992; accepted Dec. 22, 1992.

We thank Steve Watt for technical assistance. We are grateful to Angeles Ribera and Xiaonan Gu for their critical reviews of the manuscript. M.G.D. is a Fellow of the CNRS. Supported by a NATO grant to M.G.D. and NIH NS25916 and NSI 5918 to N.C.S.

Correspondence should be addressed to Nicholas C. Spitzer, Department of Biology and Center for Molecular Genetics, University of California at San Diego, 9500 Gilman Drive, La Jolla, CA 92093.

- Present address: Laboratoire de Neurobiologie Endocrinologique, URA 1197 , CNRS, Université de Montpellier II, 34095 Montpellier Cedex S, France.

Copyright (c) 1993 Society for Neuroscience $0270-6474 / 93 / 132575-07 \$ 05.00 / 0$
}

vestigated in only a few instances (Takahashi et al., 1971; Miyazaki et al., 1972, 1974; Hirano and Takahashi, 1987; Simoncini et al., 1988; Fuchs and Sokolowski, 1990; Shidara and Okamura, 1991). Thus, the extent to which differentiation in vitro parallels that in vivo is largely unknown. Further, the loss of cell-cell interactions and truncation of nascent axons and dendrites in the process of acute dissociation may alter the excitability of intact neurons.

Calcium and potassium currents play a major role in the differentiation of the action potential of Xenopus spinal neurons in culture (Barish, 1986; O'Dowd et al., 1988; Ribera and Spitzer, 1989; Lockery and Spitzer, 1992). However, the extent to which they do so in vivo is at present indirectly inferred. In cultures prepared from neural plate stage embryos, neurons become morphologically identifiable within $6 \mathrm{hr}$ after plating. At this time action potentials are long lasting and principally calcium dependent, and trigger fluctuations of intracellular calcium concentration. These properties of initial action potentials are developmentally significant since blockade of calcium influx disrupts differentiation (Bixby and Spitzer, 1984; Holliday and Spitzer, 1990; Desarmenien and Spitzer, 1991; Holliday et al., 1991). By the end of the first day in vitro, progressive development of outward potassium currents has reduced the duration of the action potential and the associated influx of calcium ions. Development of the action potential in vitro parallels that seen in vivo (Spitzer and Lamborghini, 1976; Baccaglini and Spitzer, 1977; Blair, 1983; O’Dowd, 1983), but differences in expression of individual currents could escape detection in this comparison.

We have investigated the differentiation in vivo of macroscopic currents in spinal neurons of Xenopus embryos. For this purpose, we isolated spinal cords from embryos at various stages and recorded neuronal currents in situ within $1 \mathrm{hr}$. The short experimental time was critical to minimize further differentiation and enable study of characteristics of the currents resulting from developmental events in vivo prior to isolation. We focused on calcium and on potassium currents, which play major roles in triggering and controlling the duration of action potentials (Gu and Spitzer, 1991; Lockery and Spitzer, 1992). Results were compared to those previously obtained in primary cultures from neural plates of Xenopus embryos. Whole-cell voltage clamp of neurons in acutcly isolated and intact embryonic spinal cord demonstrates that both the delayed-rectifier and inactivating potassium current and a low-voltage-activated (LVA) calcium current mature in situ in a manner very similar to that observed for ncurons in culture. The ability to study embryonic spinal neurons both in intact preparations as well as in dissociated cell culture will promote further studies of the developmental significance of calcium signaling. 

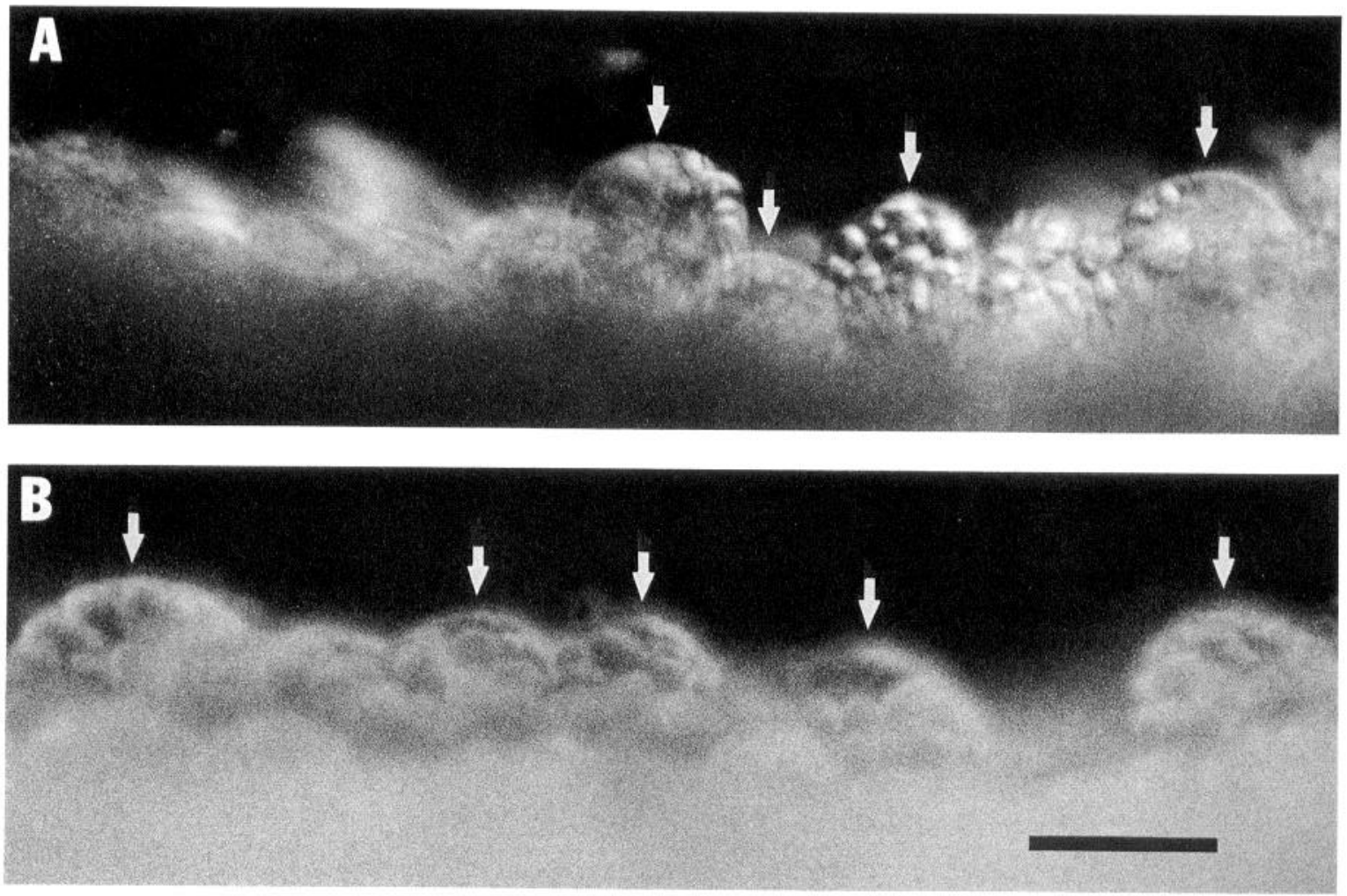

Figure 1. The isolated Xenopus spinal cord: photomicrographs of spinal cords dissected from embryos at stages 24 ( $A$, neural tube) and 36 ( $B$, hatching). Cords were oriented with the dorsal aspect uppermost; cell bodies of laterally situated interneurons are indicated by arrows. Scale bar,
$25 \mu \mathrm{m}$.

\section{Materials and Methods}

Spinal cord preparation. Xenopus embryos were obtained by hormoneinduced mating and staged according to the normal table of Nieuwkoop and Faber (1967). The dorsal one-third of a single embryo (stages 2240 ), including spinal cord, notochord, and surrounding lateral mesoderm, was dissected in a standard medium containing (in mM) $\mathrm{NaCl}$, 116.6; $\mathrm{KCl}, 0.67 ; \mathrm{MgSO}_{4}, 1.31 ; \mathrm{CaCl}_{2}, 10$; and Tris, 4.6, $\mathrm{pH}$ 7.8. The ectoderm was removed and tissues were exposed to collagenase (Boehringer; $1 \mathrm{mg} / \mathrm{ml}$ ) in low-divalent-containing medium (in mM: $\mathrm{NaCl}$, $116.6 ; \mathrm{KCl}, 0.67 ; \mathrm{CaCl}_{2}, 0.5 ; \mathrm{HEPES}, 8, \mathrm{pH} 7.8$ ). This procedure enabled manual separation of the spinal cord from the somites and the notochord. Once isolated, the spinal cord was rinsed three times in standard medium and transferred to the recording chamber, consisting of a 35 $\mathrm{mm}$ culture dish coated with a thin layer of Sylgard. Washes and transfer were carried out under visual observation to track the orientation of the isolated spinal cord, which was then fixed in a groove, dorsal aspect uppermost, using glass needles.

Cell selection. Recordings were made from the dorsolateral part of the cord. Neurons present in this region are mainly interneurons, with cell bodies of $20 \mu \mathrm{m}$ diameter and processes that grow to only $100 \mu \mathrm{m}$ in length in larval stages (Roberts and Clarke, 1982). Their geometry is similar to that of interneurons in dissociated cell culture (Lamborghini and Iles, 1985; Spitzer et al., 1988), which are frequently sufficiently spatially compact to be well clamped (O'Dowd et al., 1988; Ribera and Spitzer, 1990; Desarmenien and Spitzer, 1991). Dorsal Rohon-Beard cells and ventral motor neurons were both avoided, since their long processes were expected to prevent adequate control of membrane potential; the opacity of the tissue at early stages also reduced the quality of transillumination and made it difficult to visualize cells closer to the midline. In addition, only the anterior one-third of the cord was studied to restrict the heterogeneity of cell birthdates at the stages of development examined (Nordlander, 1989) and achieve greater uniformity in the age of the population studied.

Cells were identified as neurons on the basis of functional and morphological criteria. At the start of a recording, a fast inward transient current was observed in standard culture medium, presumably carried by sodium ions. This current was the same size as the sodium current recorded in neurons at equivalent stages of development in culture, with the same voltage dependence and kinetics. Sodium currents recorded from glia often have different properties from those of neurons and are generally smaller in amplitude (Barres et al., 1990). In addition, at the end of recording, gentle retraction of the pipette withdrew the cell from the cord and revealed the presence of processes. Cells were scored as neurons only when both criteria were met.

Biophysical techniques. Neurons were visualized directly at $500 \times$ magnification using Nomarski optics. Neuronal currents were recorded at room temperature $\left(20-22^{\circ} \mathrm{C}\right)$, using the whole-cell configuration of the patch-clamp technique (Hamill et al., 1981); series resistance (mean of $5.6 \pm 0.2 \mathrm{M} \Omega, n=90$ ) was compensated $>60 \%$ (Dagan $8900 \mathrm{am}$ plifier). Pipettes were pulled from Drummond hematocrit capillary tubes and fire polished, and had resistances of 2-5 M $\Omega$ (mean of 3.4 \pm 0.1 $\mathrm{M} \Omega$ ). The level of bath saline was kept low, avoiding the necessity to reduce capacitance by coating pipettes with Sylgard. Potassium currents were digitized at $50 \mu \mathrm{sec}$; calcium T-currents were digitized at $40 \mu \mathrm{sec}$ (first $30 \mathrm{msec}$ ) and $100 \mu \mathrm{sec}$ (thereafter, see Fig. 4). Experiments were performed and analyzed using pCLAMP software (Axon Instruments).

An initial recording was obtained in standard medium and the fast inward current was used to test the adequacy of the clamp. Cells were rejected if there were delays in activation, the presence of several peaks, or bumps on the rising or falling phase. The medium was then changed to one containing tetrodotoxin (TTX) and cobalt chloride to block inward currents. The delayed-rectifier potassium current $\left(I_{\mathrm{Kv}}\right)$ was recorded in response to depolarizing steps from a holding potential of $-40 \mathrm{mV}$ at which much of the A-current is inactivated. The rapidly inactivating potassium A-current $\left(I_{K_{\Lambda}}\right)$ was derived by subtraction of current traces obtained by depolarization from holding potentials of -40 and $-80 \mathrm{mV}$ (Ribera and Spitzer, 1990). Low-voltage-activated calcium current $\left(I_{\mathrm{Car}}\right)$ was elicited by depolarization to potentials positive to $-60 \mathrm{mV}$ from a holding potential of $-100 \mathrm{mV}$, in medium containing tetraethylammonium chloride (TEA) to suppress potassium currents (Gu and Spitzer, 1991, and unpublished observations). Series resistance was determined from the peak current in response to a 10 $\mathrm{mV}$ depolarizing step $18 \mathrm{msec}$ in duration (digitized at $33 \mathrm{kHz}$ ), and 
A
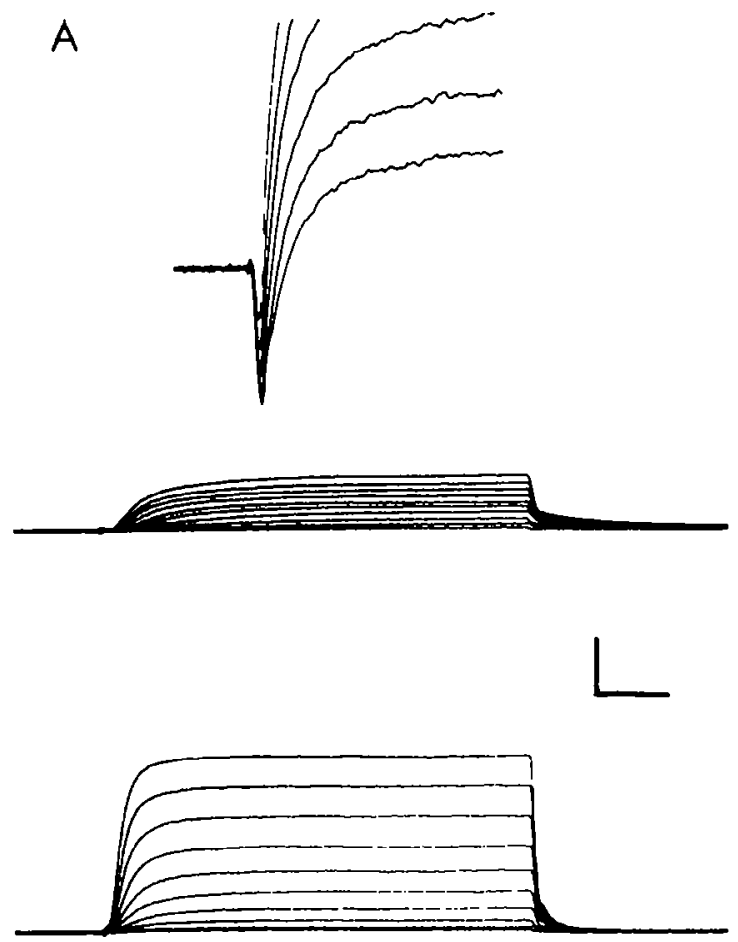

D

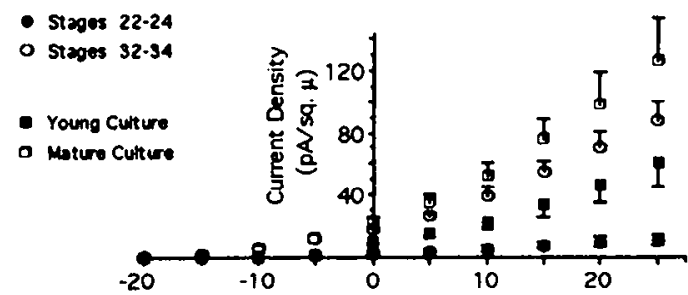

E

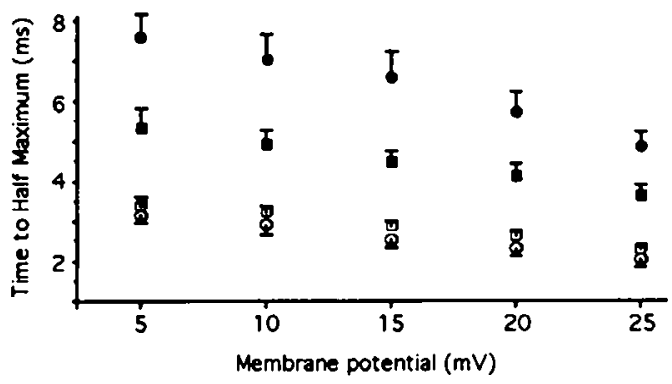

the time constant of the capacitative transient was fit with an exponential. Monoexponential decay confirmed the sufficiency of voltage-clamp control. Since the cell resistance (mean of $1.1 \pm 0.2 \mathrm{G} \Omega, n=90$ ) is much greater than the series resistance $(5.6 \mathrm{M} \Omega)$, cell capacitance was obtained as the quotient of the time constant with the serics resistance (mean of $20.6 \pm 0.6 \mathrm{pF}$ ). This value did not change appreciably during the developmental period studied, presumably reflecting a rather small contribution by neurites that grow out during this time (see also O'Dowd et al., 1988). Current density was derived by dividing the current by
B

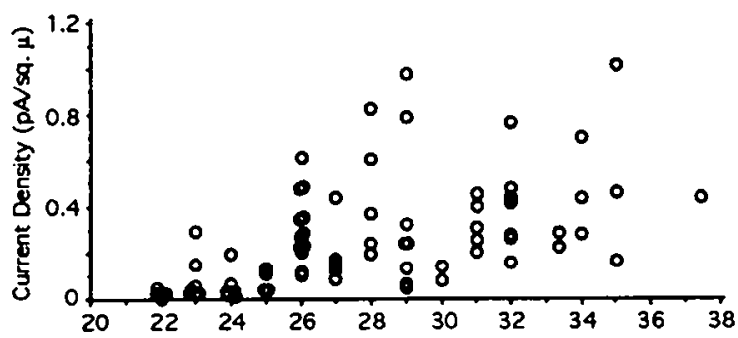

C

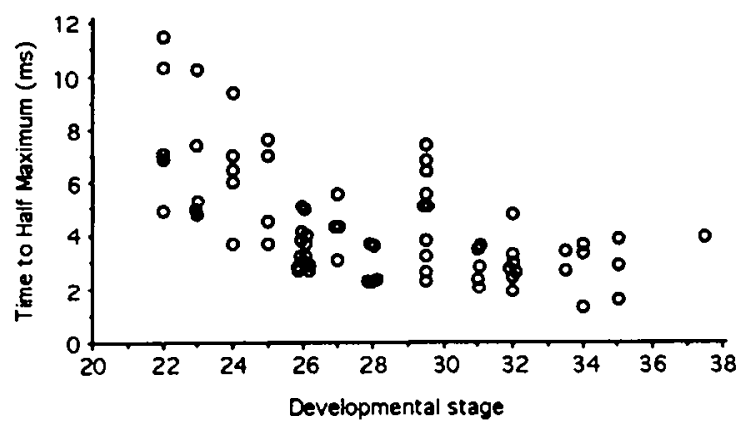

Figure 2. Properties of delayed-rectifier potassium currents $\left(I_{\mathrm{Kv}}\right)$ recorded from young and mature neurons in the spinal cord of the developing Xenopus embryo. $A$, Currents first recorded in standard culture medium (stage 29-30; top); calibration is $300 \mathrm{pA}$ and $2 \mathrm{msec}$. Depolarization elicits a fast inward current, demonstrating the adequacy of the clamp, followed by sustained outward current. The membrane potential was held at $-80 \mathrm{mV}$ and stepped to voltages from 0 to $+25 \mathrm{mV}$ in increments of $5 \mathrm{mV}$. Also shown are currents evoked by depolarizations from $-40 \mathrm{mV}$ in young (stage 24 ; middle) and mature (stage 38 ; bottom) cells. Voltage steps ranged from -20 to $+25 \mathrm{mV}$ in increments of $5 \mathrm{mV}$; calibration is $200 \mathrm{pA}$ and $5 \mathrm{msec} . B$ and $C$, Current density and time to half-maximum are plotted as a function of age. Cells were held at $-40 \mathrm{mV}$ and stepped to $+10 \mathrm{mV}$. $D$ and $E$, Comparison of cells recorded in situ and in neuron-enriched cultures at two different stages of development. Current density and time to half-maximum are plotted as a function of membrane potential. Values are means \pm SEM for $n=7-20$; holding potential, $-40 \mathrm{mV}$. Values for cultures are from Desarmenien and Spitzer (1991).

the cell surface membrane area assuming a membrane capacitance of $1 \mu \mathrm{F} / \mathrm{cm}^{2}$ (O'Dowd et al., 1988).

Solutions. To facilitate direct comparison of results, recording media used in this study were the same as those employed previously to study these currents in cultured cells. Potassium currents were recorded in a medium containing (in $\mathrm{mM}$ ) $\mathrm{NaCl}, 80 ; \mathrm{KCl}, 3 ; \mathrm{MgCl}_{2}, 5 ; \mathrm{CoCl}_{2}, 10$; and HEPES, 5, pH adjusted to 7.4 with $\mathrm{NaOH}$; TTX was used at $6 \times 10^{-7}$ $M$. The pipette solution was (in $\mathrm{mM}$ ) $\mathrm{KCl}, 80 ; \mathrm{KOH}, 3$; EGTA, 10; and HEPES, 10, pH adjusted to 7.4 with $\mathrm{KOH}$. For recording calcium cur- 

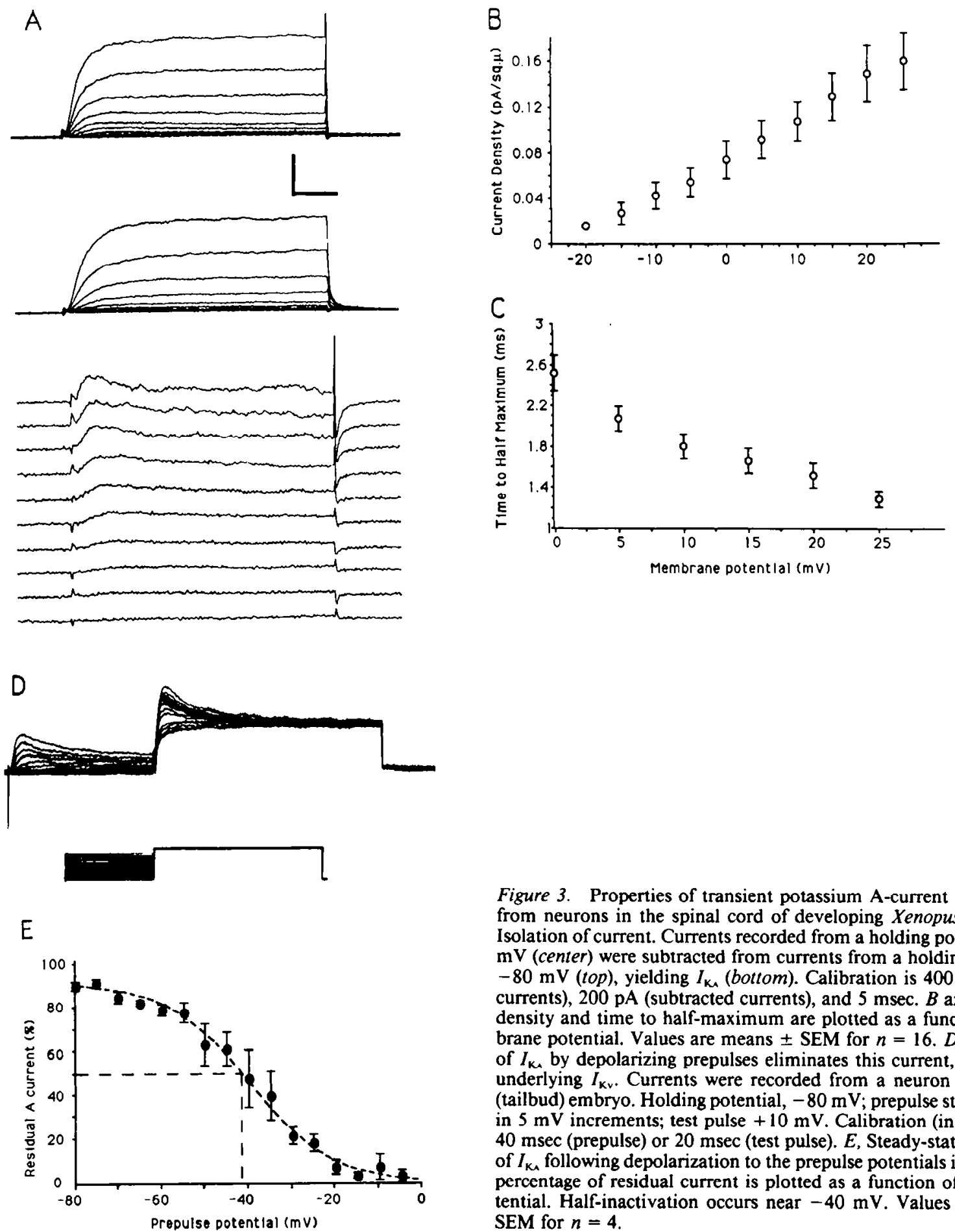

Figure 3. Properties of transient potassium A-current $\left(I_{\mathrm{K}_{1}}\right)$ recorded from neurons in the spinal cord of developing Xenopus embryos. $A$, Isolation of current. Currents recorded from a holding potential of -40 $\mathrm{mV}$ (center) were subtracted from currents from a holding potential of $-80 \mathrm{mV}$ (top), yielding $I_{\mathrm{K}_{4}}$ (bottom). Calibration is $400 \mathrm{pA}$ (recorded currents), $200 \mathrm{pA}$ (subtracted currents), and $5 \mathrm{msec} . B$ and $C$, Current density and time to half-maximum are plotted as a function of membrane potential. Values are means \pm SEM for $n=16 . D$, Inactivation of $I_{k}$ by depolarizing prepulses eliminates this current, revealing the underlying $I_{\mathrm{kv}}$. Currents were recorded from a neuron in a stage 28 (tailbud) embryo. Holding potential, $-80 \mathrm{mV}$; prepulse steps to $-5 \mathrm{mV}$ in $5 \mathrm{mV}$ increments; test pulse $+10 \mathrm{mV}$. Calibration (in $A$ ), $1 \mathrm{nA}$ and $40 \mathrm{msec}$ (prepulse) or $20 \mathrm{msec}$ (test pulse). $E$, Steady-state inactivation of $I_{\mathrm{Ka}}$ following depolarization to the prepulse potentials indicated. The percentage of residual current is plotted as a function of prepulse potential. Half-inactivation occurs near $-40 \mathrm{mV}$. Values are means \pm SEM for $n=4$.

rents, the bath solution contained (in $\mathrm{mm}$ ) $\mathrm{NaCl}, 80 ; \mathrm{CaCl}_{2}, 2 ; \mathrm{KCl}, 3$; TEA, 40; and HEPES, 5, pH adjusted to 7.4 with $\mathrm{NaOH}$; TTX, $6 \times$ 10 ' $\mathrm{M}$. The pipette solution was (in mM) $\mathrm{CsCl}$, 95; EGTA, 10; TEA, $10 ;$ ATP-Mg, 2; cAMP, 2 ; and HEPES, $10, \mathrm{pH}$ adjusted to 7.4 with $\mathrm{CsOH}$.

\section{Results}

The isolated embryonic spinal cord allows clear visualization of relatively large single cells along its lateral margins (Fig. 1). As many as 20 neuronal candidates can be identified in a single preparation. Whole-cell recording from these cells indicated that

$78 \%$ met the criteria for neurons $(n=128$ of 164$)$, and had rapidly activated and inactivated presumptive sodium current as well as neurites. Of these, $77 \%$ were sufficiently well clamped to enable further examination.

\section{Potassium currents}

The delayed-rectifier potassium current $\left(I_{\mathrm{KV}}\right)$ was isolated by pharmacologically blocking inward sodium and calcium currents and holding cells at $-40 \mathrm{mV}$, a potential at which $I_{\mathrm{k}}$ is largely inactivated. Under these conditions no tail currents were 
observed at a holding potential equal to the equilibrium potential for potassium ions $(-84 \mathrm{mV})$. Further, the recorded current was similar to the outward delayed-rectifier current in cultured neurons (Fig. 2A; O'Dowd et al., 1988; Desarmenien and Spitzer, 1991). $I_{\mathrm{K}}$ was studied in 75 cells, between stages 22 and 38 . These stages correspond to the neural tube embryo and tailbud larva.

Both the density and kinetics of $I_{\mathrm{k} v}$ underwent developmental changes similar to those observed for neurons differentiating in vitro. However, comparison with data from neuron-enriched cultures at the same developmental stages (Desarmenien and Spitzer, 1991) revealed that there were subtle differences as well. First, the increase in current density was greater in vivo $(9 \times$ vs $2 \times)$, although the voltage dependence of activation remained constant (Fig. 2B,D). Smaller absolute values of current at early stages accounted for most of the difference, even after normalization for cell size. Currents were also smaller at later stages of development in the spinal cord than in neuron-enriched cultures. However, comparison with data from $24 \mathrm{hr}$ mixed cultures of neurons and myocytes, a condition that more closely approximates development in vivo, showed a current density comparable to that from the oldest embryos studied (Desarmenien and Spitzer, 1991). Second, the time to half-maximum activation of the current decreased during development and the extent of the decrease was larger in vivo than in vitro as the result of larger initial values. However, the values obtained in neurons from the oldest embryos were comparable to those reported for $24 \mathrm{hr}$ neuron-enriched cultures (Fig. 2C,E) and for mixed cultures (Desarmenien and Spitzer, 1991).

The rapidly inactivating potassium current $\left(I_{\mathrm{K}_{A}}\right)$ was isolated by subtraction of current traces obtained at holding potentials of -40 and $-80 \mathrm{mV}$ (Fig. $3 A$; Ribera and Spitzer, 1990). The development of the A-current is delayed with respect to $I_{\mathrm{K}}$; it was first detected in embryos at stage $26,6 \mathrm{hr}$ after stage 22 . The proportion of cells displaying A-current increased progressively with further development. At stage 32-34 (corresponding to $24 \mathrm{hr}$ in culture), the current was present in five of cight cells. Voltage dependence of activation and current density were similar to those reported for neurons in culture, as was the rate of activation (Fig. $3 B, C$ ). This current inactivated rapidly at depolarized potentials. The voltage dependence of steady-state inactivation of $I_{k}$ paralleled that reported for cells in vitro (Fig. $3 D, E)$. The delayed development of $I_{K_{A}}$ with respect to $I_{\mathrm{KV}}$ has been previously observed for neurons in vitro (Ribera and Spitzer, 1990).

\section{Calcium current}

The LVA calcium current $\left(I_{\mathrm{CaT}}\right)$ was elicited by depolarization to potentials positive to $-60 \mathrm{mV}$ from a holding potential of $-100 \mathrm{mV}$ (Fig. 4A). Calcium currents were studied in 24 cells at developmental stages $22-40 . I_{C_{\text {aT }}}$ also inactivated rapidly following activation. The voltage dependence and rate of activation of this current (Fig. 4B,C) were similar to those of the T-current recorded in culture (Gu and Spitzer, 1991, and unpublished observations). The density of the current increased during development while the time to half-maximum showed a slight decrease.

\section{Discussion}

The present work was undertaken to evaluate in vivo development of voltage-dependent ionic currents in Xenopus spinal neurons. Much of the information concerning development of
A
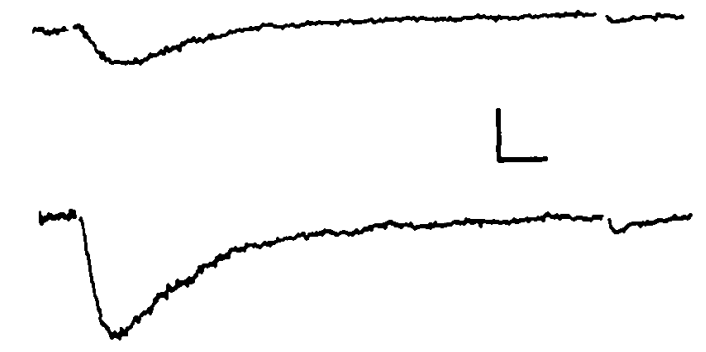

B

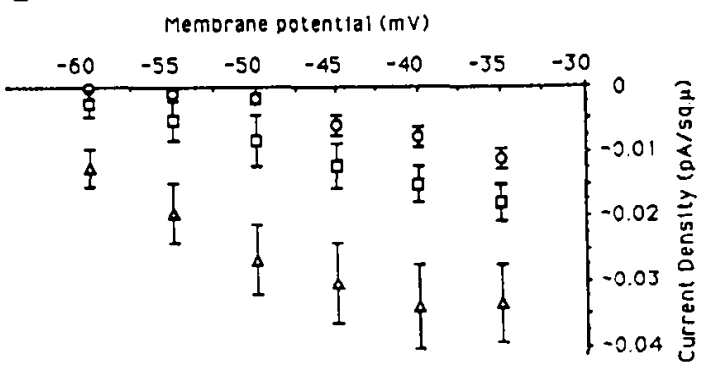

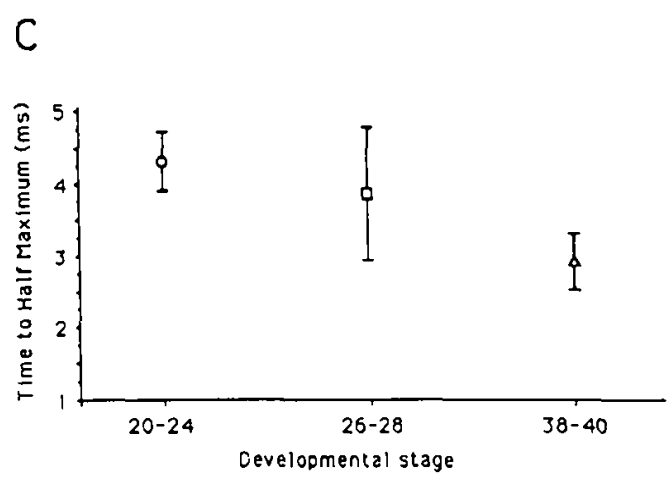

Figure 4. Properties of LVA calcium currents $\left(I_{C_{\mathrm{a}}}\right)$ recorded from young and mature neurons in the spinal cord of developing Yenopus embryos. $A$, Currents recorded from young (stage 23) and mature (stage $37-38$ ) cells following depolarization to $-40 \mathrm{mV}$ from a holding potential of $-100 \mathrm{mV}$. Calibration is $60 \mathrm{pA}$ and $1 \mathrm{msec}$. $B$, Current density as a function of voltage at three different developmental stages [20-24 $(O), 26-28(\square)$, and 38-40 $(\triangle)$ ]. Values are means \pm SEM for $n=6-9$; holding potential, $-100 \mathrm{mV}$. $C$, Time to half-maximum as a function of developmental stage. Values are means \pm SEM for $n=4-7$; holding potential, $-100 \mathrm{mV}$, step to $-40 \mathrm{mV}$.

excitability in these embryonic neurons is inferred from recordings of action potentials in vivo and of ionic currents in vitro. We focused first on the delayed-rectifier potassium current $\left(I_{\mathrm{kv}}\right)$, which controls the duration of action potentials and activity-dependent calcium influx during neurogenesis (Lockery and Spitzer, 1992; for review, see Holliday and Spitzer, 1991). In culture, the development of $I_{\mathrm{K}}$ is composed of increases in density and rate of activation. Both require RNA synthesis during a critical period, and the maturation of kinetics requires the activity of calcium-dependent protein kinase C (Ribera and Spitzer, 1989; Desarmenien and Spitzer, 1991). Here we show that $I_{\mathrm{K}}$ undergoes developmental changes in vivo like those reported in culture during the same period. In addition, we observe the progressive appearance of the rapidly inactivating A-current and a slight increase in density and rate of activation 
of the low-threshold calcium current. Importantly, the in vivo characteristics of the currents confirm conclusions drawn from analysis of differentiation in primary cultures.

The whole-cell configuration of the patch-clamp technique was first applied successfully to cultured cells (Hamill et al., 1981), and the method has been more recently applied to cells in slices and in the intact nervous system (Blanton et al., 1989; Sakmann et al., 1989). Here we demonstrate that high-resistance seals are easily formed on cells in the spinal cord, and wholecell recordings up to an hour in duration were obtained. The absence of extensive connective tissue at the developmental stages studied may have contributed to the ability to form gigaseals without extensive enzyme treatment. Recordings were generally made from cells in the external layer, although deeper neurons could be recorded after removal of superficial ones with a patch pipette.

Neurite arborizations are not easily visualized in the intact but isolated spinal cord, and it is difficult to select cells with geometries that are spatially compact. In consequence, the adequacy of control of the membrane potential was critically evaluated in each cell before proceeding with further analysis. Cells were selected on the basis of the activation characteristics of a fast (presumably sodium) inward current. This selection assumes that the ionic channels supporting the current under study have the same membrane distribution as sodium channels. In all cells considered for analysis, $I_{\mathrm{Kv}}$ showed smooth activation curves and a tail current that was abolished near the equilibrium potential for potassium ions. $I_{\mathrm{KA}}$ and $I_{\text {Сат }}$ were similarly smoothly activated. On this basis, the data presented were obtained from well-clamped cells.

The developmental changes in the delayed-rectifier current reported from primary cultures are qualitatively similar to those recorded in vivo. Moreover, the proportion of cells exhibiting an A-current is similar in $24 \mathrm{hr}$ cultures and in stage 32-34 embryos. However, some quantitative differences in $I_{\mathrm{Kv}}$ were observed. Primary cultures from Xenopus embryonic spinal cords contain predominantly early birthdate motoneurons, RohonBeard cells, and some interneurons. These cultures are relatively homogeneous with respect to neuronal birthdates (Lamborghini, 1980; Lamborghini and Iles, 1985), and no further neuronal precursor DNA synthesis or mitosis occurs. For the in vivo condition, the sample of neurons includes further, younger cells, resulting from the continuous addition of neurons to the growing population (Hartenstein, 1989). The variability in current density and time to half-maximum in cells of the same stage is likely to be a reflection of the variability of birthdates. In young embryos, the mean current density is smaller and the rate of activation slower than in $6 \mathrm{hr}$ cultures, consistent with this process.

In older embryos, at a time when the generation of primary neurons is complete (Hartenstein, 1989), the mean current density is also smaller than in neuron-enriched cultures at the same developmental age. However, a more appropriate comparison of these in vivo recordings from older embryos with those from mixed cultures at the same stage (Desarmenien and Spitzer, 1991 ) indicates that the density and the rate of rise of $I_{\mathrm{Kv}}$ are the same in vitro as for ncurons in vivo. Voltagc-depcndent currents in myocytes have also been shown to be regulated by the presence of neural factors (DeCino and Kidokoro, 1985; Ribera and Spitzer, 1991).

The development of $I_{\mathrm{K} v}, I_{\mathrm{KA}}$, and $I_{\mathrm{Car}}$ in vivo parallels their development in culture. The developmental changes in these currents play a significant role in further neuronal differentiation in vitro. For example, the progressive maturation of potassium currents decreases the duration of calcium-dependent action potentials that are triggered by activation of the low-threshold calcium current (Gu and Spitzer, 1991; Lockery and Spitzer, 1992). Maturation of potassium currents also suppresses the calcium component of action potentials in cultured embryonic rat and chick cortical and brain nuclear neurons (Ahmed et al., 1983; Mori-Okamoto et al., 1983; Pettigrew et al., 1988), rat sympathetic ganglion cells (Nerbonne and Gurney, 1989), and chick motoneurons (McCobb et al., 1990), as well as murine neuroblastoma and rat PC12 cells (Dichter et al., 1977; Miyake, 1978; Ritchie, 1979; O'Lague and Huttner, 1980). Calcium T-current can decrease in amplitude or disappear during further development (Kostyuk, 1989; McCobb et al., 1989). Calciumdependent action potentials in embryonic Xenopus spinal neurons induce elevations of the intracellular calcium concentration at early stages of development in culture, which control subsequent differentiation (Holliday et al., 1991; see Holliday and Spitzer, 1991, for review). It will be of interest to examine the spontaneous elevations of intracellular calcium of neurons differentiating in situ.

\section{References}

Ahmed Z, Walker PS, Fellows RE (1983) Properties of neurons from dissociated fetal rat brain in serum-free culture. J Neurosci 3:24482462.

Baccaglini PI, Spitzer NC (1977) Developmental changes in the inward current of the action potential of Rohon-Beard neurones. J Physiol (Lond) 271:93-117.

Barish ME (1986) Differentiation of voltage-gated potassium current and modulation of excitability in cultured amphibian spinal neurons. J Physiol (Lond) 375:229-250.

Barres BA, Chun LLY, Corey DP (1990) Ion channels in vertebrate glia. Annu Rev Neurosci 13:441-474.

Bixby JL, Spitzer NC (1984) Early differentiation of vertebrate spinal neurons in the absence of voltage-dependent $\mathrm{Ca}^{++}$and $\mathrm{Na}^{+}$influx. Dev Biol 106:89-96.

Blair LAC (1983) The timing of protein synthesis required for the development of the sodium action potential in embryonic spinal neurons. J Neurosci 3:1430-1436.

Blanton MG, Lo Turco JJ, Kriegstein AR (1989) Whole cell recording from neurons in slices of reptilian and mammalian cerebral cortex. J Neurosci Meth 30:203-210.

DeCino P, Kidokoro Y (1985) Development and subsequent neural tube effects on the excitability of cultured Xenopus myocytes. J Neurosci 5:1471-1482.

Desarmenien MG, Spitzer NC (1991) Role of calcium and protein kinase $C$ in development of the delayed rectifier potassium current in Xenopus spinal neurons. Neuron 7:797-805.

Dichter MA, Tischler AS, Greene LA (1977) Nerve growth factorinduced increase in electrical excitability and acetylcholine sensitivity of a rat pheochromocytoma cell line. Nature 268:501-504.

Fuchs P, Sokolowski B (1990) The acquisition of Ca-activated potassium currents by cochlear hair cells of the chick. Proc R Soc Lond [Biol] 241:122-126.

Gu X, Spitzer NC (1991) T-type $\mathrm{Ca}^{2+}$ current and its function in triggering $\mathrm{Ca}^{2+}$ influx in embryonic Xenopus spinal neurons. Soc Neurosci Abstr 17:1159.

Hamill OP, Marty A, Neher E, Sakmann B, Sigworth FJ (1981) Improved patch clamp technique for high resolution current recording from cells and cell-free membrane patches. Pfluegers Arch 391:85100.

Hartenstein V (1989) Early neurogenesis in Xenopus: the spatio-temporal pattern of proliferation and cell lineages in the embryonic spinal cord. Neuron 3:399-411.

Hirano T, Takahashi K (1987) Development of ionic channels and cell-surface antigens in the cleavage-arrested one-cell embryo of an ascidian. J Physiol (Lond) 386:113-133.

Holliday J, Spitzer NC (1990) Spontaneous calcium influx: roles in differentiation of spinal neurons in culture. Dev Biol 141:13-23. 
Holliday J, Spitzer NC (1991) Calcium channels in the regulation of cell development and cellular interactions. In: Calcium channels: their properties, functions, regulation and clinical relevance (Hurwitz $\mathrm{L}$, Partridge LD, Leach JK, eds), pp 137-155. Boca Raton, FL: CRC.

Holliday J, Adams RJ, Sejnowski TJ, Spitzer NC (1991) Calciuminduced release of calcium regulates differentiation of cultured spinal neurons. Neuron 7:787-796.

Kostyuk PG (1989) Diversity of calcium ion channels in cellular membranes. Neuroscience 28:253-261.

Lamborghini J (1980) Rohon-Beard cells and other large neurons in Xenopus embryos originate during gastrulation. J Comp Neurol 189: 323-333.

Lamborghini JE, lles A (1985) Development of a high-affinity GABA uptake system in embryonic amphibian spinal neurons. Dev Biol 112: 167-176.

Lockery SR, Spitzer NC (1992) Reconstruction of action potential development from whole cell currents of differentiating neurons. J Neurosci 12:2268-2287.

McCobb DP, Best PM, Beam KG (1989) Development alters the expression of calcium currents in chick limb motoneurons. Neuron 2:1633-1643.

McCobb DP, Best PM, Beam KG (1990) The differentiation of excitability in embryonic chick limb motoneurons. J Neurosci 10:29742984.

Miyake M (1978) The development of action potential mechanism in a mouse neuronal cell line in vitro. Br Res 143:349-354.

Miyazaki S, Takahashi K, Tsuda K (1972) Calcium and sodium contributions to regenerative responses in the embryonic excitable cell membrane. Science 176:1441-1443.

Miyazaki S, Takahashi K, Tsuda K, Yoshii M (1974) Analysis of nonlinearity observed in the current-voltage relation of the tunicate embryo. J Physiol (Lond) 238:55-57.

Mori-Okamoto J, Ashida H, Maru E, Tatsuno J (1983) The development of action potentials in cultures of explanted cortical neurons from chick embryos. Dev Biol 97:408-416.

Nerbonne JM, Gurney AM (1989) Development of excitable membrane properties in mammalian sympathetic neurons. J. Neurosci 9 : 3272-3286.

Nieuwkoop PD, Faber J (1967) Normal table of Xenopus laevis (Daudin): a systematic and chronological survey of the development of the fertilized egg till the end of metamorphosis, $2 \mathrm{~d}$ ed. Amsterdam: North Holland.

Nordlander RH (1989) HNK-1 marks earliest axonal outgrowth in Xenopus. Dev Brain Res 50:147-153.
O'Dowd DK (1983) RNA synthesis dependence of action potential development in spinal cord neurones. Nature 303:619-621.

O'Dowd DK, Ribera AB, Spitzer NC (1988) Development of voltagedependent calcium, sodium and potassium currents in Xenopus spinal neurons. J Neurosci 8:792-805.

O'Lague PH, Huttner SL (1980) Physiological and morphological studies of rat pheochromocytoma cells (PCI2) chemically fused and grown in culture. Proc Nat Acad Sci 77:1701-1705.

Pettigrew AG, Crepel F, Krupa M (1988) Development of ionic conductances in neurons of the inferior olive in the rat: An in vitro study. Proc R Soc Lond B 234:199-218.

Ribera AB, Spitzer NC (1989) A critical period of transcription required for differentiation of the action potential of spinal neurons. Neuron 2:1055-1062.

Ribera AB, Spitzer NC (1990) Differentiation of $I_{\mathrm{K}}$ in amphibian spinal neurons. J Neurosci 10:1886-1891.

Ribera AB, Spitzer NC (1991) Development of the delayed rectifier potassium current in embryonic Xenopus myocytes. Dev Biol 144: 119-128.

Ritchie A (1979) Catecholamine secretion in a rat pheochromocytoma cell line: Two pathways for calcium entry. J Physiol 286:541-561.

Roberts A, Clarke DW (1982) The neuroanatomy of an amphibian embryo spinal cord. Philos Trans R Soc Lond [Biol] 296:195-212.

Sakmann B, Edwards F, Konnerth A, Takahashi T (1989) Patch clamp techniques used for studying synaptic transmission in slices of mammalian brain. Q J Exp Physiol 74:1107-1118.

Shidara M, Okamura Y (1991) Developmental changes in delayed rectifier $\mathrm{K}^{+}$currents in the muscular- and neural-type blastomere of ascidian embryos. J Physiol (Lond) 443:277-305.

Simoncini L, Block ML, Moody WJ (1988) Lineage-specific development of calcium currents during embryogenesis. Science 242:15721575.

Spitzer NC (1991) A developmental handshake: neuronal control of ionic currents and their control of neuronal differentiation. J Neurobiol 22:659-673.

Spitzer NC, Lamborghini JE (1976) The development of the action potential mechanism of amphibian neurons isolated in culture. Proc Natl Acad Sci USA 73:1641-1645.

Spitzer NC, deBaca RC, Holliday J (1988) Developmental acquisition of GABA-like immunoreactivity by amphibian spinal neurons differentiating in vitro. Soc Neurosci Abstr 14:163.

Takahashi KS, Miyazaki S, Kidokoro Y (1971) Development of excitability in embryonic muscle cell membranes in certain tunicates. Science 171:415-418. 